\title{
Mapping Evidence of Experiential learning for Primary Health Care Workers in Low-and-Middle-Income Countries: A Scoping Review
}

\author{
Nkosinothando Chamane ${ }^{1}$, Desmond Kuupiel ${ }^{1} \&$ Tivani Phosa Mashamba-Thompson ${ }^{1}$ \\ ${ }^{1}$ Department of Public Health Medicine, School of Nursing and Public Health, University of KwaZulu-Natal, \\ Durban, South Africa \\ Correspondence: Nkosinothando Chamane, Department of Public Health Medicine, School of Nursing and Public \\ Health, University of KwaZulu-Natal, Durban, South Africa. Tel: 27-760-133-775. E-mail: \\ thandocharmane@yahoo.com
}

Received: July 8, 2019 Accepted: August 12, 2019 Online Published: September 25, 2019

doi:10.5539/gjhs.v11n12p1 URL: https://doi.org/10.5539/gjhs.v11n12p1

\begin{abstract}
Background: Improving equity of healthcare is one of the main global health priorities, particularly in low and medium-income-countries (LMICs). However, most LMICs still struggle to achieve equity in healthcare provision. One of the major contributing factors to achieving health equity in these settings include low levels of healthcare competency among primary healthcare workers. Experiential learning has been shown to contribute effectively to healthcare curriculum delivery. The purpose of this study was to systematically map evidence of experiential learning training programs for PHC workers with a focus on quality improvement in LMICs.
\end{abstract}

Findings: Of the 240022 articles retrieved from database search, 129 studies were found to be eligible for inclusion in abstract screening following title screening. Subsequent to abstract screening, 29 articles were eligible for inclusion in full article screening. Full article screening resulted in four articles found eligible for inclusion for data extraction and quality appraisal. Included studies were conducted in the following Countries: South Africa, China and Brazil. The following themes emerged: The utility, efficiency and acceptability of experiential learning approaches to PHC workers and Reflection. Experiential learning through various approaches was shown to have the potential to provide an important practical aspect on curriculum delivery not easily taught in lecture-based learning. Skills developed by PHC students in LMICs included communication, empathy, creativity and critical-reflexive skills. The reflection step of experiential learning was shown to be a useful tool to identify root causes of health systems inefficiencies and to inform policy making. The quality of included studies was found to range from above average to high quality.

Conclusion: Limited research on the utility, efficiency and acceptability of experiential learning approaches to PHC-based professionals as well as on the impact of these approaches to the provision of quality services was found. Research focused on the development and piloting of experiential learning approaches to determine feasibility and to ensure effectiveness of interventions towards continuous professional development and life-long learning of PHC nurses in rural clinics is recommended.

Keywords: experiential learning, low and middle-income-countries, primary health care

\section{Background}

Provision of quality health care services for all is a global health priority (McNernery, 2015). However, this has been found to be a challenge to achieve in resource-limited settings (Gaede \& Versteeg, 2011; Gray et al., 2007; Jaya, Drain, \& Mashamba-Thompson, 2017). Factors contributing to the challenges related to quality service delivery in low and medium-income-countries (LMICs) include incompetency of health professionals, lack of continuous professional development (CPD) initiatives, poor access to laboratory infrastructure due to clinics being situated in deep rural areas, time constraints and lack of motivation to engage in new interventions (R. H. Gray et al., 2007; Jaya, Drain, \& Mashamba-Thompson, 2017; Kuupiel, Bawontuo, \& Mashamba-Thompson, 2017; Munyewende \& Rispel, 2014). Health professionals' incompetency has been shown to have a negative impact on the quality of the services they provide (D. Moodley, P. Moodley, Ndabandaba, \& Esterhuizen, 2008). Provision of CPD for primary health care (PHC) workers is also a challenge in LMICs, due to poor access to training resources as well as working in poor conditions that are not conducive for training. These include space limitations and staff shortages (Arunachallam, 2009). Experiential learning can afford PHC workers in resource-limited setting opportunities of continuous development they are limited from, when implemented well 
(A. Y. Kolb \& D. A. Kolb, 2009).

Many definitions of experiential learning can be found in literature, but in its simplest form, experiential learning can be defined as learning achieved through the appropriate use of current experience (Allodola, 2014). In this study we define experiential learning as learning which focuses on the learner's experiences and the subsequent reflection on them, which promotes deeper learning and application of content knowledge. The experiential learning theory (ELT) provides a holistic model of the learning process and a multi-linear model of professional development, which is consistent with what is known about how people learn, and develop (A. Y. Kolb \& D. A. Kolb, 2003). The experiential learning model is a step-by-step process of learning that can be adapted to suit different environments. The reflective writing step was found to be an important step that can be used to identify gaps in medical education for resource-limited settings (Dhital et al., 2015).

Sustainable Development Goal (SDG) 3.8 emphasizes the importance of access to safe, effective, quality and affordable essential medicines and vaccines for all. To achieve this goal it is crucial that the competency of health care professionals is maintained (Wirtz et al., 2016). SDG 4 also calls for the need of quality education for all and promotion of lifelong learning. Lifelong learning for professionals can be achieved through departmental CPD programs, which is an essential characteristic of a profession and lasts throughout the individual's personal and professional experience (Arunachallam, 2009). CPD programs can be implanted using a variety of methods including experiential learning. Experiential learning has multiple benefits, including opportunities of reflection; continuous professional development as well as life-long learning.

Various experiential learning-based curricula have been designed and used successfully for training health professionals (Allodola, 2014), however the level of evidence on its implementation on PHC workers in LMICs is not clear. This study therefore aims to map available literature on the implementation of experiential learning training programs for PHC workers with a focus on quality improvement in LMICs. It is anticipated that the evidence provided in this study will contribute to the existing body of knowledge on the utility, efficiency, and acceptability of experiential learning for PHC health workers in LMICs as well as guide future research.

\section{Methodology}

\subsection{Study Design}

We chose a scoping review as the most appropriate method to address our research question. Scoping reviews have become an increasingly popular approach for synthesizing research evidence, they are also useful in mapping existing literature and identifying research gaps to guide future research (Arksey \& O'Malley, 2005). The protocol of this scoping review was developed and accepted for peer-review and publication (Chamane, Kuupiel, \& Mashamba-Thompson, 2019). This scoping review is part of a larger implementation research study, which is aimed at determining the feasibility of implementing an experiential learning training programme for point-of-care (POC) diagnostics in PHC clinics in rural KwaZulu-Natal, South Africa. This review is guided by Arksey and O'Malley's scoping review framework (Arksey \& O'Malley, 2005), which was enhanced by Levac et al., 2010 (Levac, Colquhoun, \& O'Brien, 2010). We followed the PRISMA SCr (Preferred Reporting Items for Systematic Reviews and Meta-Analyses Scoping review) guidelines to report the results of this review We also included a quality appraisal of the included primary studies.

\subsection{Identifying the Research Question}

The research question for the scoping review is: What evidence is available on experiential learning for PHC workers in LMICs?

The PCC (Population, Context and Concept) nomenclature was adopted to determine the eligibility of the research question for a scoping review study (Table 1).

Table 1. PCC for determining eligibility of the research question

\begin{tabular}{ll}
\hline Criteria & \multicolumn{1}{c}{ Determinants } \\
\hline Population & PHC workers (all category of nurses, councillors, student nurses and public health students) in LMICs \\
Concept & Experiential learning training programs (onsite training, field-based experiences and participatory learning) \\
Context & Quality improvement \\
\hline
\end{tabular}

\subsection{Identifying Relevant Studies}

The scoping review included primary studies with clear empirical evidence, utilising quantitative, qualitative and/or mixed methods, peer reviewed papers in published journals, and grey literature such as unpublished thesis 
and WHO training guides and policies. To identify relevant studies, an electronic search was conducted in the following databases: PubMed, Google Scholar, EBSCOhost (Academic search complete, Health Source: Nursing/Academic Addition, MEDLINE) and open access for unpublished theses and dissertations. The World Health Organisation (WHO), the departments of health and the HealthSETA websites were also searched for policies and guidelines for experiential learning training programs. Studies were identified by searching literature published in any language from inception to 2018. The search keywords were "primary health care", "experiential learning" and "low and middle-income-countries". MeSH (Medical Subject Headings) terms were also included during the search.

\subsection{Study Selection}

The primary investigator conducted a comprehensive search and screening of the study titles from the above-mentioned databases. All studies with eligible titles were exported to an Endnote X8 library, which was specifically created for this review. Duplicates and electronic books (ebooks) were removed from the library before commencing abstract screening. Abstract screening and full text screening tools developed using google forms, were piloted before being used to screen the articles. Abstract screening was conducted by two reviewers (N.C and A.M) independently with guidance from the eligibility criteria. Following abstract screening, all eligible studies were retrieved for full article screening by NC and AM. The University of KwaZulu-Natal (UKZN) library services were utilised to optimise retrieving of included studies, which were not accessible from the selected databases. Discrepancies in reviewers' results at abstract screening were resolved by a discussion among the review team until consensus was reached. Discrepancies in reviewer's results at full article screening were resolved by involving a third reviewer (TS). We employed STATA version 13 to compute Kappa statistics and McNemar's chi-square to determine the degree of agreement between screener's results after full article screening. Significant results were reported at $\mathrm{p} \geq 0.01$. The screening results are reported using the adapted PRISMA flow chart.

\subsection{Eligibility Criteria}

The following eligibility criteria was utilized to ensure that selected studies contain relevant information to answer our research question:

\subsubsection{The Inclusion Criteria}

Studies that present evidence on the following were included:

- Primary Health Care workers: frontline nurses, councillors and student nurses

- Experiential learning programs in primary health care

- Onsite/in-house training programs in primary health care

- Studies conducted in LMICs

- $\quad$ Studies published from inception to 2018

2.5.2 Exclusion Criteria

The scoping review excluded:

- Studies that presented evidence of experiential learning on nurses in tertiary healthcare settings.

- Studies conducted in high income countries.

- Literature reviews, opinion papers and ebooks.

\subsection{Data Charting}

A data extraction tool was developed using google forms to extract information relevant to answering the research question: what evidence is available on experiential learning for ensuring PHC quality service delivery in LMICs? The tool included the following study characteristics: authors and year of publication; aims, research questions, study population, level of qualification, geographic setting, study design, theoretical background, evidence of experiential learning as an intervention, evidence of experiential learning outcomes (Utility, efficiency and acceptability), and most relevant findings. The data extraction tool was piloted and validated by involving a second reviewer (TPM-T).

\subsection{Quality Appraisal}

The Mixed Methods Appraisal Tool (MMAT) version 2018 was adopted to assess the quality of included primary studies, for the purpose of evaluating the risk of bias (Hong et al., 2018). The MMAT allows for quality appraisal and description of methodological quality for three methodological domains: mixed methods, qualitative and quantitative (further subdivided into three sub-domains: randomized controlled, nonrandomized, and descriptive). 
The tool was piloted by two reviewers (NC and DK). The quality of the included studies was assessed according to the relevant methodological domain in the tool. The MMAT was used to examine the appropriateness of study aims, the context relevance, and theoretical inferences to answer research questions. The overall quality for each of the included studies was calculated following the MMAT guidelines (score $=$ number of criteria met/5) and then presented using the following descriptors: low quality (20\%), where minimal criteria was met, average (50-60\%), above average (80\%), high quality $(100 \%)$, where all criteria was met. Two reviewers (NC and DK) performed quality appraisal of included studies and discrepancies were resolved through a team discussion until consensus was reached.

\subsection{Collation and Summary of Results}

To collate and report the scoping review findings, three distinct steps were followed as guided by Levac et al. (Levac et al., 2010). The steps were: analysing the data, reporting results, and applying meaning to the results. This involved a descriptive numerical summary, characteristics of included studies and a thematic analysis (Arksey \& O'Malley, 2005).

Thematic content analysis was conducted using the following themes:

- The utility of experiential learning approaches for PHC workers

- The acceptability of experiential learning for PHC workers

- The efficiency of the experiential learning approach on quality service delivery at PHC level

In this study, we have defined utility of experiential learning in terms of its application to training and development of PHC workers. We have defined efficiency of experiential learning in terms of its ability to add value to the competency of PHC workers as well as to the improvement of services provided in the PHC clinics situated in resource limited settings. We have defined acceptability of experiential learning in terms of its contribution to continuous professional development and lifelong learning.

Additional findings emerging from significant findings of the included studies were reported as emerging themes. These were analysed, critically examining how they contribute to answering the main research question. The review team met to discuss the findings, resolve discrepancies and finalise results. The review team also analysed the implications of the findings in relation to the aim of the study, future research and evidential framework for policy and application in LMICs.

\section{Results}

\subsection{Screening Results}

Figure 1 depicts the screening results for this scoping review. A total of 240022 studies were retrieved from the databases search, where after a comprehensive search and screening of the study titles a total of 143 studies were found eligible for inclusion (Appendix A). During title screening 14 duplicates were also removed and 129 studies were thus included for abstract screening. Following abstract screening, 100 articles were excluded as they did not meet the inclusion criteria of this study. Therefore, 29 articles were included for full article screening. Following full article screening 25 articles were excluded, resulting in four articles eligible for inclusion in data extraction and quality appraisal.

A total of 25 articles were excluded following full article screening because of the following reasons: 19 articles were conducted in high income countries (Baum, Li, \& Usher, 2000; Becker, Walton-Moss, \& Hanyok, 2015; D'Lugoff \& McCarter, 2005; Dornan, Scherpbier, \& Boshuizen, 2009; Higgins, 1999; Kokotailo, Langhough, Neary, Matson, \& Fleming, 1995; A. Y. Kolb \& D. A. Kolb, 2003; Langridge \& Hauck, 1998; Lockhart \& Resick, 1997; Macaulay et al., 1999; Manley, Titchen, \& Hardy, 2009; McDonald, Jackson, Wilkes, \& Vickers, 2012; Pagano \& Roselle, 2009; Plsek \& Greenhalgh, 2001; Stanley, Al-Shehri, \& Thomas, 1993; Thornley, 2000; Thorpe, 2004; Wallace, 1996; Wright, 2000); four articles did not present evidence on the population of interest to this scoping review (Pagano \& Roselle, 2009; Prose, Diab, \& Matthews, 2013; Stanley et al., 1993; Tess et al., 2009), one article presents evidence on our target population but did not provide evidence of experiential learning (Evans \& Ndirangu, 2011) and; one article was an opinion piece and proposing a framework for experiential learning for PHC nurses in resource limited settings (Mashamba-Thompson, Sartorius, Stevens, \& Drain, 2016).

Analysis of full article screening results showed that there was $82.14 \%$ agreement versus $62.76 \%$ expected by chance which constitutes a considerably moderate to high agreement between screener's results (Kappa statistic = -0.52 and p-value $<0.01)$. In addition, the McNemar's chi-square statistic suggests that there was no statistically significant difference in the proportions of yes/no answers by reviewer with p-value $>0.01$ (Appendix C). 


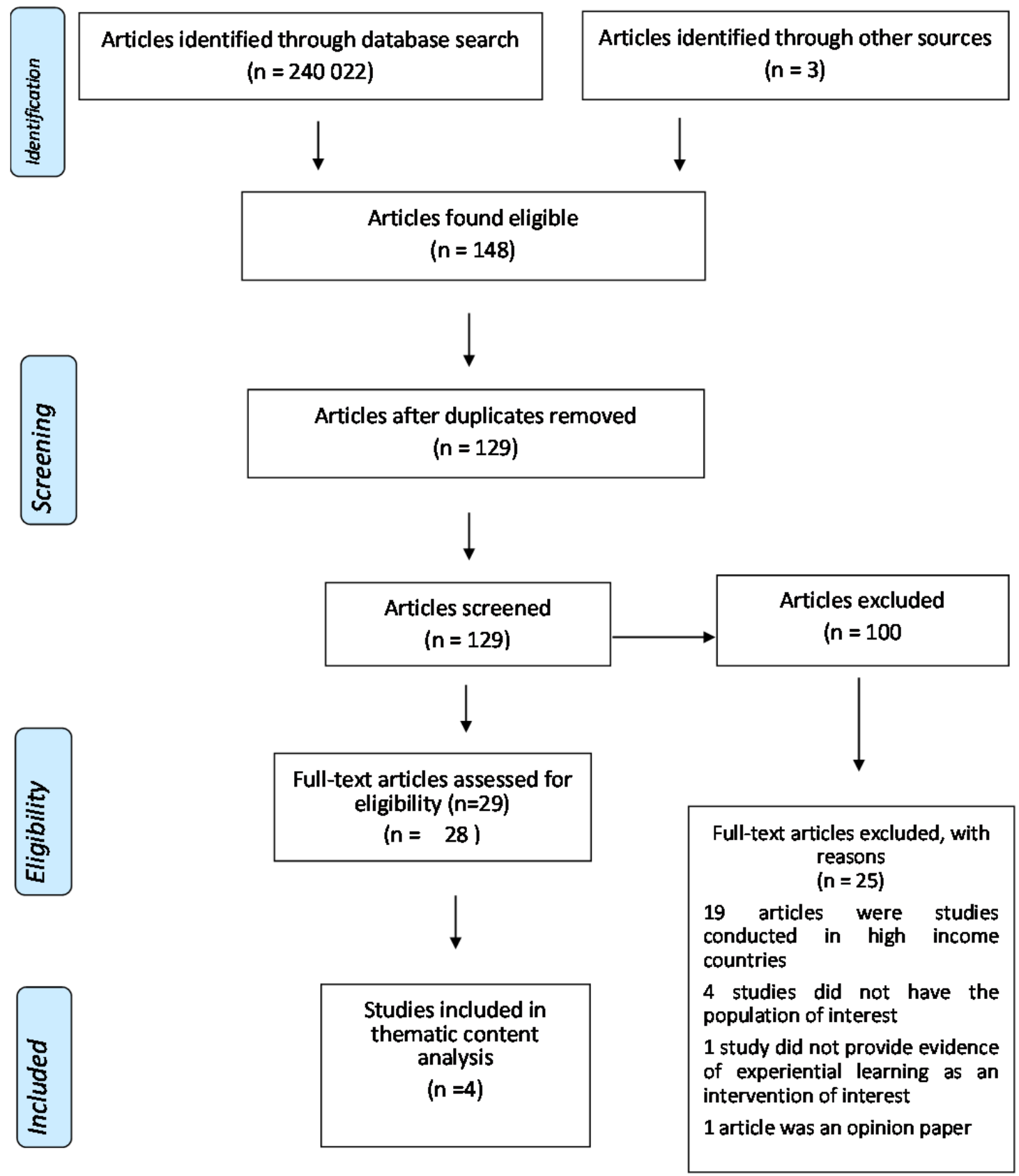

Figure 1. PRISMA SCr flow chart showing literature search and selection of studies

\subsection{Characteristics of Included Studies}

The characteristics of the four included studies are presented in Table 2. All included studies reported evidence of experiential learning in LMICs published between the years 2010 and 2015 (de Oliveira et al., 2015; Hu, Abraham, Mitra, \& Griffiths, 2015; Munyewende \& Rispel, 2014; Prose et al., 2013; Wee, Yeo, Tay, Lee, \& Koh, 2010). The included studies were conducted in the following LMICs: Brazil; South Africa; and China. Three articles reported on studies conducted on PHC-based healthcare students (nursing and public health students) (de Oliveira et al., 2015; Hu et al., 2015; Prose et al., 2013; Wee et al., 2010) and one article reported evidence on the reflection step of experiential learning among nursing managers (Munyewende \& Rispel, 2014).

Two studies were conducted in urban settings (de Oliveira et al., 2015; Wee et al., 2010), one study in a rural setting (Hu et al., 2015) and one study in both the urban and rural setting (Munyewende \& Rispel, 2014). Three different approaches utilising experiential learning were presented in the included studies, namely: clinical simulations (de Oliveira et al., 2015), field studies (Hu et al., 2015), and public health screenings (PHS) (Wee et al., 2010). 
1 Table 2. Characteristics of the included studies and study findings

\begin{tabular}{|c|c|c|c|c|c|c|c|}
\hline Author, Year & Population(n) & Country & Setting & Study Design & Intervention & Research Aims & Outcome \\
\hline $\begin{array}{l}\text { de Oliveria et } \\
\text { al., } 2015\end{array}$ & $\begin{array}{l}\text { Nursing } \\
\text { Students }\end{array}$ & Brazil & Urban & $\begin{array}{l}\text { Qualitative - } \\
\text { Action } \\
\text { research }\end{array}$ & $\begin{array}{l}\text { Experiential learning } \\
\text { through clinical simulation }\end{array}$ & $\begin{array}{l}\text { To propose and to implement } \\
\text { experiential learning through } \\
\text { clinical simulation with the } \\
\text { participation of actors in } \\
\text { nursing, to help students make } \\
\text { decisions that can change and } \\
\text { improve reality. }\end{array}$ & $\begin{array}{l}\text { The proposal and implementation of experiential } \\
\text { learning through } \\
\text { clinical simulation with undergraduate nursing } \\
\text { students proved to be a rich and appropriate } \\
\text { process of training professionals to develop } \\
\text { creative and critical-reflexive skills }\end{array}$ \\
\hline Hu et al., 2015 & $\begin{array}{l}\text { Public health } \\
\text { students }\end{array}$ & China & Rural & Qualitative & $\begin{array}{l}\text { Experiential learning } \\
\text { through an Action research } \\
\text { approach }\end{array}$ & $\begin{array}{l}\text { International Field Studies (IFS) } \\
\text { course to give graduate level } \\
\text { public health students an } \\
\text { opportunity to visit low-income } \\
\text { countries to learn from } \\
\text { experience and exposure. }\end{array}$ & $\begin{array}{l}\text { The field study provided students with } \\
\text { first-hand insights into issues such as how } \\
\text { primary care services are delivered, an } \\
\text { understanding of the impact of environment and } \\
\text { poverty on a large scale, as well as, the } \\
\text { challenges of a rapidly developing economy of } \\
\text { Bangladesh. }\end{array}$ \\
\hline $\begin{array}{l}\text { Munyewende, } \\
2015\end{array}$ & $\begin{array}{l}\text { PHC nursing } \\
\text { managers }\end{array}$ & $\begin{array}{l}\text { South } \\
\text { Africa }\end{array}$ & $\begin{array}{l}\text { Rural } \\
\text { and } \\
\text { Urban }\end{array}$ & Qualitative & $\begin{array}{l}\text { Reflection step of } \\
\text { Experiential learning }\end{array}$ & $\begin{array}{l}\text { To explore the work experiences } \\
\text { of PHC clinic nursing managers } \\
\text { through the use of reflective } \\
\text { diaries. }\end{array}$ & $\begin{array}{l}\text { Identification of some of the root causes to some } \\
\text { of the health system inefficiencies. A } \\
\text { recommendation for policy-makers to address } \\
\text { these in a participatory manner was made. }\end{array}$ \\
\hline Wee, 2010 & $\begin{array}{l}\text { Medical } \\
\text { Nursing } \\
\text { students }\end{array}$ & China & Urban & Quantitative & $\begin{array}{l}\text { A student-led } \\
\text { community-based } \\
\text { experiential learning project } \\
\text { referred to as the Public } \\
\text { Health Screening (PHS) }\end{array}$ & $\begin{array}{l}\text { Assessing the pedagogical value } \\
\text { of Public Health Screenings } \\
\text { (PHS) to students to obtain } \\
\text { insights into the learning that } \\
\text { may be derived from such } \\
\text { projects. }\end{array}$ & $\begin{array}{l}\text { Majority of nursing students who participated } \\
\text { felt that PHSs helped them to improve and learn } \\
\text { in all areas, with most agreeing that they helped } \\
\text { them to clearly understand the criteria for } \\
\text { recommending patients to undergo screening } \\
\text { tests as well as to develop communication, } \\
\text { listening and negotiation skills }\end{array}$ \\
\hline
\end{tabular}




\section{Summary of Findings}

Thematic content analysis was conducted and the findings are reported according to the following themes: The utility, efficiency and acceptability of experiential learning approaches for PHC workers and Reflection. Below is a detailed narrative presentation of evidence on the above themes.

\subsection{The Utility of Experiential Learning Approaches for PHC Workers}

Three of the four included studies reported evidence on the utility of experiential learning approaches in LMICs (de Oliveira et al., 2015; Hu et al., 2015; Wee et al., 2010). The following experiential learning approaches were shown to form part of the health care students training: clinical simulations (de Oliveira et al., 2015), field studies (Hu et al., 2015) and public health screenings (PHS) (Wee et al., 2010).The proposal and implementation of experiential learning through clinical simulation with undergraduate nursing students proved to be a rich and appropriate process of training students to develop creative and critical-reflexive skills (de Oliveira et al., 2015). $\mathrm{Hu}$ et al. (2015) study, conducted in Bangladesh has shown that field studies provided students with first-hand insights into issues such as delivery of primary care services, have impact on the environment and on witnessing poverty on a large scale, as well as on the challenges of a rapidly developing economy (Hu et al., 2015). Wee et al., 2010, has shown that the PHS approach can help students improve and learn in all areas, with most agreeing that the program helped them to clearly understand the criteria for recommending patients to undergo screening tests as well as to develop communication, listening and negotiation skills (Wee et al., 2010). Our findings show that there is limited research on the utility of experiential learning as an approach of training PHC professionals as participants, three of the four included studies reported on experiential learning for students.

\subsection{The Efficiency of Experiential Learning Approaches on PHC Workers}

Two of the included studies (de Oliveira et al., 2015; Wee et al., 2010) reported evidence on the efficiency of experiential learning approaches on PHC workers. Experiential learning through clinical simulations was shown to be an important step in vocational training; facilitating training through experience as well as providing training on quality and patient safety (de Oliveira et al., 2015). Experiential learning through PHS was shown to be an effective tool in teaching empathy and concern for the community, and that the students highly valued learning in these areas. This indicates that student initiated and organised community-based experiential learning projects have potential value in meeting the educational needs of nursing students, not just to learn clinical competencies but also to acquire softer skills such as pro-activeness and appreciation of the challenges faced by the lower income groups.

The two included studies also revealed experiential learning approaches to be more efficient when used as a supplementary approach (de Oliveira et al., 2015; Wee et al., 2010). Wee et al. (2010) found their experiential learning project to be less effective in teaching clinical procedures and therefore, recommended that this learning approach should supplement and not replace traditional pedagogical methods of PHC health care teaching and training (Wee et al., 2010). De' Oliveira et al., 2015 also highlighted that simulated practice and/or experiential learning do not replace real context, but enrich learning and offers students the opportunity to perceive patients as unique individuals with personal ways of dealing with diseases (de Oliveira et al., 2015). These two studies stated that experiential learning should be seen as a tool of giving students an opportunity to acquire valuable skills that are not easily taught in a lecture-based setting (de Oliveira et al., 2015; Wee et al., 2010). Only one study presented evidence on the reflection step of experiential learning with PHC professional as participants, hence demonstrating a gap in research aimed at determining the efficiency of experiential learning approaches for PHC-based workers.

\subsection{Acceptability of Experiential Learning for PHC-Based Workers}

In this study, the acceptability of experiential learning was defined in terms of its contribution to CPD and lifelong learning. Evidence presented by the included studies on these aspects is reported below.

\section{Experiential learning contribution to continuous professional development and lifelong learning}

Two of the included studies reported evidence on the contribution of experiential learning to lifelong learning (de Oliveira et al., 2015; Wee et al., 2010). Experiential learning through clinical simulation was shown to enable active search for knowledge, which awakens critical thinking and promote reflection as well as contribute to the student's overall development throughout life (de Oliveira et al., 2015). PHS allowed students to participate in designing, organisation and implementation of the overall projects, helping them acquire leadership skills and the ability to take action as they continued with service delivery (Wee et al., 2010). Evidence shows that there is limited research on the effect of experiential learning on student's development of lifelong learning skills when students' progress to the work environment. 


\subsection{Reflection}

Two of the included studies reported evidence focusing on the reflection step of experiential learning (Hu et al., 2015; Munyewende \& Rispel, 2014). This step was shown to be a useful tool for identifying root causes of health systems inefficiencies as well as for assisting in improving the curriculum and informing of future policies (Munyewende \& Rispel, 2014). It was also shown that field studies gave students first-hand experience and their reflections thereof, can guide development of future courses (Hu et al., 2015). The findings largely demonstrate that a wealth of knowledge can be acquired through written reflections. However there is limited research on the reflections of PHC workers in rural settings.

\section{Quality Appraisal}

Quality assessments of three included primary studies was conducted, (de Oliveira et al., 2015; Munyewende \& Rispel, 2014; Wee et al., 2010) one of the included studies was a secondary study and hence could not be assessed (Hu et al., 2015). Of the three studies assessed two (67\%) were qualitative studies (de Oliveira et al., 2015; Munyewende \& Rispel, 2014) and one (33\%) was a quantitative descriptive study (Wee et al., 2010). The results of the MMAT quality appraisal showed that $67 \%$ of the assessed studies scored $80 \%$ and were thus of above average quality (de Oliveira et al., 2015; Munyewende \& Rispel, 2014). One (33\%) study scored $100 \%$ and was shown to be of high quality (Wee et al., 2010). The overall evidence was considered to have minimal risk of bias and the overall quality of included studies ranges between above average and high quality (Hong et al., 2018).

\section{Discussion}

This study has mapped available evidence on the utility, efficiency and acceptability of experiential learning training programs as well as its impact on the quality of services provided by PHC workers in LMICs (nurses, nursing students, medical students and public health students). The findings of the review show that experiential learning approaches have been successfully utilised in various projects, with students as participants: clinical simulations, field studies, and public health screenings (PHS). The utility of these approaches was shown to be appropriate for training PHC healthcare students to achieve desired learning outcomes. These approaches were also shown to be effective in contributing to continuous skills development and lifelong learning, and hence responding to the first two research questions of this study (de Oliveira et al., 2015; Hu et al., 2015; Wee et al., 2010). Experiential learning through various approaches as reported in this study has the potential to provide an important practical aspect on curriculum delivery not easily taught in a lecture-based learning, however knowledge on the efficiency of these approaches on professional PHC nurses in LMICs is limited, since majority of the included studies was conducted on students (de Oliveira et al., 2015; Wee et al., 2010). Reflection defined as a tool to help take a careful inventory of events or situations (Pagano \& Roselle, 2009), was also shown to contribute towards identification of root causes of health systems inefficiencies and to help in improving the curriculum and in informing of future policies and courses. This is a very critical and necessary aspect to be considered for institutional continuous development. Although experiential education emerged as a recognised field of education since the 1970s (D. R. Hammerman, W. M. Hammerman, \& E. L. Hammerman, 2007), only one study reported evidence on the reflections step of experiential learning on PHC professionals in LMICs. It was also shown there is a shortage of research on experiential learning for nursing students, bearing in mind that nurses are the main custodians of PHC, this finding is a concern. There was also no evidence of research aimed to investigate the impact of experiential learning approaches on quality service delivery at PHC level. This is also a concern and a limitation in research.

The findings of this study are consistent with studies conducted in higher income countries (Marriot, Lipus, \& al., 2015; Pagano \& Roselle, 2009). These studies also revealed that experiential learning provides students with first-hand insights into issues such as delivery of primary care services. Pagano, et al. 2009 emphasized that the goal of experiential learning is to expose students to a practice that enhances the knowledge of subject matter, practice, as well as the culture of that particular community (Pagano \& Roselle, 2009). A study involving community members in a high-income country showed that using participatory based learning programs like experiential learning can strengthen community research partnerships as well as provide valuable training experiences for current and aspiring health personnel. (Marriott et al., 2015). A study conducted in Nepal on medical students also showed that the reflective writing step of experiential learning can contribute to identify and address gaps in medical education for resource limited settings (Dhital et al., 2015). Moreover, when reflection is done correctly, it can help organisations move towards further steps, which include critical thinking and decision making to improve knowledge attainment as well as service delivery (Pagano \& Roselle, 2009). A previous case study on nurses and midwives by McDonald et., al 2012 also revealed that there were limited research studies on work-based interventions that provide opportunities for clinical nurses to take time away from their challenging 
work environments and focus on elements that could improve their experiences of work (McDonald et al., 2012). In comparison to other traditional models of teaching and learning for PHC workers, experiential learning was shown to be more efficient when used as a supplementary approach. However it was shown to be less effective in teaching carrying out of clinical procedures, therefore recommended to supplement and not replace traditional pedagogical methods of teaching in PHC (de Oliveira et al., 2015; Wee et al., 2010). This is also consistent with findings of a study conducted in a high-income country on nursing graduate students (D'Lugoff \& McCarter, 2005). In that study the students involved in experiential outreach activities voiced that the opportunities provided were consistent with their course work adding a valuable, supplemental practice component (D'Lugoff \& McCarter, 2005). In contrary to these findings, an international systematic review study found that traditional continuing medical education and passive distribution of information is not effective, and educational outreach programs are effective, however they can be very but time consuming and expensive (Allodola, 2014). On the same subject Kolb et al., 2009 also show that experiential learning can afford PHC workers in resource limited setting opportunities of continuous development they are limited from, when implemented well (A. Y. Kolb \& Kolb, 2009).

This study provided high quality evidence that experiential learning approaches were useful and efficient in providing practical experiences to supplement traditional training models, moreover they have the potential to provide CPD opportunities to PHC workers in resource limited settings. The potential experiential learning programs have to provide an important practical aspect on curriculum delivery not easily taught in a lecture-based learning, has however not been fully determined on PHC professionals in LMICs since majority of the included studies consisted of PHC students as participants.

\subsection{Strengths and Limitations}

The strengths of this study include an extensive search for relevant studies, which included the use of Boolean terms and MeSH terms to increase chances of finding eligible studies. In addition, the full article screening tool was piloted resulting in increased reliability. All included primary studies underwent quality appraisal using an approved tool; the Mixed Method Appraisal Tool (MMAT) for methodological assessment of the included primary studies. The overall evidence was considered to have minimal risk of bias and the overall quality of included studies ranged between above average and high quality. Despite the above-mentioned strengths, there were some limitations due to discrepancies between reviewers at full article screening however, a third screener was invited to assist in resolving them.

\subsection{Recommendations for Future Research}

The findings of this study show that there is limited research on the utility and/or efficiency of experiential learning approaches on PHC professional as participants in LMICs. We recommend more studies of this nature. Considering that no studies reported on the impact of experiential learning approaches on quality service delivery at PHC level in LMIC, future pilot and primary studies are recommended. We also recommend future research focused on development and piloting of experiential learning approaches to determine feasibility and ensure effectiveness of interventions to ensure continuous professional development and life-long learning. Qualitative studies on the day-today reflections of health care workers are also recommended to identify root courses of deficiencies in relation to experiential learning as well as to guide policy development.

\subsection{Implications for practice}

Considering the true gap revealed on the limited CPD programs suitable for PHC professionals in resource limited settings as well as the positive outcomes of experiential learning approaches on PHC students shown in this study, it would be advisable and beneficial for the government in LMICs to invest on primary research studies on the implementation of continuous professional development programs based on experiential learning in resource-limited settings.

\section{Conclusion}

The findings of this study indicate that the utility of experiential learning approaches through various educational projects is an appropriate process of training healthcare students to develop creative and critical-reflexive skills not easily taught in a lecture-based setting. The reflection step was shown to be a useful tool to identify root causes of health systems inefficiencies as well as to inform policy making. In relation to other traditional education models, experiential learning was shown to be more effective in providing for softer skills and thus recommended as a supplement to provide for the practical aspects of training. Research on the utility, the efficiency and acceptability of these approaches to PHC-based professionals and the effect these have on the quality of service delivery was found to be very limited and is recommended for future research.

\section{Acknowledgements}


The authors would like to acknowledge the systematic review services within the College of Health Sciences, University of KwaZulu-Natal for training and for screening services.

\section{Authors' Contributions}

NC and TPM-T conceptualised the study. NC conducted database searches and title screening. NC, AM and TS contributed in abstract and full article screening, as well as in piloting the tools for data extraction and quality appraisal. DK assisted with quality appraisal. NC prepared the first draft of the manuscript. TPM-T and DK critically reviewed the draft. All authors approved of the final draft.

\section{Competing Interests Statement}

The authors declare that there are no competing or potential conflicts of interest.

\section{References}

Allodola, V. F. (2014). The effects of educational models based on experiential learning in Medical Education: an international literature review. Tutor, 14(4), 23-49. https://doi.org/10.14601/Tutor-14725

Arksey, H., \& O'Malley, L. (2005). Scoping studies: towards a methodological framework. International Journal of Social Research Methodology, 8(1), 19-32. https://doi.org/10.1080/1364557032000119616

Arunachallam, S. (2009). The development of a model for continuing professional development for professional nurses in South Africa. (Doctor of Philosophy), University of the Western Cape.

Baum, J. A., Li, S. X., \& Usher, J. M. (2000). Making the next move: How experiential and vicarious learning shape the locations of chains' acquisitions. Administrative Science Quarterly, 45(4), 766-801. https://doi.org/10.2307/2667019

Becker, K., Walton-Moss, B., \& Hanyok, L. A. (2015). Creating your ideal primary care practice: innovative interprofessional learning activity. J Nurs Educ, 54(5), 300. https://doi.org/10.3928/01484834-20150417-11

Chamane, N., Kuupiel, D., \& Mashamba-Thompson, T. P. (2019). Experiential learning for primary healthcare workers in low-and middle-income countries: a scoping review protocol. Systematic reviews, 8(1), 123. https://doi.org/10.1186/s13643-019-1040-6

D'Lugoff, M. I., \& McCarter, J. (2005). Learning from experience: three community health population-based outreach projects for graduate and undergraduate students. Int J Nurs Educ Scholarsh, 2, Article 17. https://doi.org/10.2202/1548-923x.1130

de Oliveira, S. N., do Prado, M. L., Kempfer, S. S., Martini, J. G., Caravaca-Morera, J. A., \& Bernardi, M. C. (2015). Experiential learning in nursing consultation education via clinical simulation with actors: Action research. Nurse Educ Today, 35(2), e50-e54. https://doi.org/10.1016/j.nedt.2014.12.016

Dhital, R., Subedi, M., Prasai, N., Shrestha, K., Malla, M., \& Upadhyay, S. (2015). Learning from Primary Health Care Centers in Nepal: reflective writings on experiential learning of third year Nepalese medical students. BMC Res Notes, 8, 741-741. https://doi.org/10.1186/s13104-015-17272

Dornan, T., Scherpbier, A., \& Boshuizen, H. (2009). Supporting medical students' workplace learning: experiencebased learning (ExBL). The Clinical Teacher, 6(3), 167-171. https://doi.org/10.1111/j.1743-498X.2009.00305.x

Evans, C., \& Ndirangu, E. (2011). Implementing routine provider-initiated HIV testing in public health care facilities in Kenya: A qualitative descriptive study of nurses' experiences. AIDS Care, 23(10), 1291-1297. https://doi.org/10.1080/09540121.2011.555751

Gaede, B., \& Versteeg, M. (2011). The state of the right to health in rural South Africa.

Gray, R. H., Makumbi, F., Serwadda, D., Lutalo, T., Nalugoda, F., Opendi, P., . . Wawer, M. J. (2007). Limitations of rapid HIV-1 tests during screening for trials in Uganda: diagnostic test accuracy study. BMJ (Clinical research ed), 335(7612), 188. https://doi.org/10.1136/bmj.39210.582801.BE

Hammerman, D. R., Hammerman, W. M., \& Hammerman, E. L. (2007). Teaching in the outdoors (5th ed.). Danville, IL: Interstate Publishers.

Higgins, J. W. (1999). Closer to home: The case for experiential participation in health reform. Canadian journal of public health, 90(1), 30-34.

Hong, Q., N., Pluy, E. P., Fàbregues, S., Bartlett, G., Boardman, F., Cargo, M., . . Vedel. (2018). Industry Canada Patent No.: C. I. P. Office. 
Hu, C. X. J., Abraham, A., Mitra, A. K., \& Griffiths, S. M. (2015). The benefits of experiential learning in global public health. Public Health (Elsevier), 136, 196-199. https://doi.org/10.1016/j.puhe.2015.10.030

Jaya, Z., Drain, P., \& Mashamba-Thompson, T. P. (2017). Evaluating quality management systems for HIV rapid testing services in primary healthcare clinics in rural KwaZulu-Natal, South Africa. PLoS ONE, 12(8), 1-17. https://doi.org/10.1371/journal.pone.0183044

Kokotailo, P. K., Langhough, R., Neary, E. J., Matson, S. C., \& Fleming, M. F. (1995). Improving pediatric residents' alcohol and other drug use clinical skills: use of an experiential curriculum. Pediatrics, 96(1), 99-104.

Kolb, A., \& Kolb, D. A. (2003). Experiential learning theory bibliography. Cleveland, OH: Experience Based Learning Systems Inc, 23, 1-40.

Kolb, A. Y., \& Kolb, D. A. (2009). The learning way: Meta-cognitive aspects of experiential learning. Simulation \& Gaming, 40, 297-327. https://doi.org/10.1177/1046878108325713

Kuupiel, D., Bawontuo, V., \& Mashamba-Thompson, T. P. (2017). Improving the Accessibility and Efficiency of Point-of-Care Diagnostics Services in Low-and Middle-Income Countries: Lean and Agile Supply Chain Management. Diagnostics, 7(4), 58. https://doi.org/10.3390/diagnostics7040058

Langridge, M. E., \& Hauck, Y. L. (1998). Perceptions of clinical role modelling: an exploration of nursing students' experiential learning. Collegian, 5(4), 22-27. https://doi.org/10.1016/S1322-7696(08)60593-4

Levac, D., Colquhoun, H., \& O'Brien, K., K. (2010). Scoping studies: advancing the methodology. Implementation Science, 5(1), 69. https://doi.org/10.1186/1748-5908-5-69

Lockhart, J. S., \& Resick, L. K. (1997). Teaching cultural competence: The value of experiential learning and community resources. Nurse Educator, 22(3), 27-31. https://doi.org/10.1097/00006223-199705000-00014

Macaulay, A. C., Commanda, L. E., Freeman, W. L., Gibson, N., McCabe, M. L., Robbins, C. M., \& Twohig, P. L. (1999). Participatory research maximises community and lay involvement. Bmj, 319(7212), 774-778. https://doi.org/10.1136/bmj.319.7212.774

Manley, K., Titchen, A., \& Hardy, S. (2009). Work-based learning in the context of contemporary health care education and practice: A concept analysis. Practice Development in Health Care, 8(2), 87-127. https://doi.org/10.1002/pdh.284

Marriot, L. K., Lipus, A. C., Choate, L., Smith, J., Coppola, L., Cameron, W. E., \& Shannon, J. (2015). Experiential Learning Through Participatory Action Research in Public Health Supports Community-Based Training of Future Health Professionals. Pedagogy in health promotion, 1, 220-232. https://doi.org/10.1177/2373379915601119

Mashamba-Thompson, T. P., Sartorius, B., Stevens, F. C. J., \& Drain, P. K. (2016). Experiential Bloom's Taxonomy learning framework for point-of-care diagnostics training of primary healthcare workers. Afr $J$ Lab Med, 5(1), 449. https://doi.org/10.4102/ajlm.v5i1.449

McDonald, G., Jackson, D., Wilkes, L., \& Vickers, M. H. (2012). A work-based educational intervention to support the development of personal resilience in nurses and midwives. Nurse Educ Today, 32(4), 378-384. https://doi.org/10.1016/j.nedt.2011.04.012

McNernery, R. (2015). Diagnostics for developing countries. MDPI AG, Basel, Switzerland, 5(2), 200-209. https://doi.org/10.3390/DIAGNOSTICS5020200

Moodley, D., Moodley, P., Ndabandaba, T., \& Esterhuizen, T. (2008). Reliability of HIV rapid tests is user dependent. South African medical journal = Suid-Afrikaanse tydskrif vir geneeskunde, 98(9), 707-709.

Munyewende, P. O., \& Rispel, L. C. (2014). Using diaries to explore the work experiences of primary health care nursing managers in two South African provinces. Global Health Action, 7(1), 1-10. https://doi.org/10.3402/gha.v7.25323

Pagano, M., \& Roselle, L. (2009). Beyond Reflection through an Academic Lens: Refraction and International Experiential Education. The Interdisciplinary Journal of Study Abroad, 18, 217-229.

Plsek, P. E., \& Greenhalgh, T. (2001). Complexity science: The challenge of complexity in health care. BMJ: British Medical Journal, 323(7313), 625. https://doi.org/10.1136/bmj.323.7313.625

Prose, N., Diab, P., \& Matthews, M. (2013). Experiential learning outside the comfort zone: Taking medical students to downtown Durban, South Africa. African Journal of Health Professions Education, 5(2). 
https://doi.org/10.7196/ajhpe.256

Stanley, I., Al-Shehri, A., \& Thomas, P. (1993). Continuing education for general practice. 1. Experience, competence and the media of self-directed learning for established general practitioners. Br J Gen Pract, 43(370), 210-214.

Tess, A. V., Yang, J. J., Smith, C. C., Fawcett, C. M., Bates, C. K., \& Reynolds, E. E. (2009). Combining clinical microsystems and an experiential quality improvement curriculum to improve residency education in internal medicine. Academic Medicine, 84(3), 326-334. https://doi.org/10.1097/ACM.0b013e31819731bf

Thornley, C. (2000). A question of competence? Re-evaluating the roles of the nursing auxiliary and health care assistant in the NHS. Journal of Clinical Nursing, 9(3), 451-458. https://doi.org/10.1046/j.1365-2702.2000.00398.x

Thorpe, K. (2004). Reflective learning journals: From concept to practice. Reflective practice, 5(3), 327-343. https://doi.org/10.1080/1462394042000270655

Wallace, D. (1996). Experiential learning and critical thinking in nursing. Nursing standard (Royal College of Nursing (Great Britain): 1987), 10(31), 43-47. https://doi.org/10.7748/ns.10.31.43.s49

Wee, L. E., Yeo, W. X., Tay, C. M., Lee, J. J., \& Koh, G. C. (2010). The pedagogical value of a student-run community-based experiential learning project: the Yong Loo Lin School of Medicine Public Health Screening. Annals Academy of Medicine Singapore, 39(9), 686.

Wirtz, V. J., Hogerzeil, H. V., Gray, A. L., Bigdeli, M., De Joncheere, C. P., \& Ewen, M. A., ... Reich, M. R (2016). Essential medicines for universal health coverage. The Lancet. http://dx.doi.org/10.1016/S0140-6736(16)31599-9

Wright, M. C. (2000). Getting more out of less: The benefits of short-term experiential learning in undergraduate sociology courses. Teaching Sociology, 116-126. https://doi.org/10.2307/1319259

\section{Appendicies}

\section{Appendix A}

\section{Screening records}

\begin{tabular}{|c|c|c|c|c|}
\hline Search Date & Data base & Keywords & $\begin{array}{l}\text { No. of } \\
\text { retrieved } \\
\text { articles }\end{array}$ & $\begin{array}{l}\text { No of } \\
\text { studies } \\
\text { eligible }\end{array}$ \\
\hline $2018-02-21$ & Pubmed & $\begin{array}{l}\text { Primary Health Care } \\
\text { and Experiential } \\
\text { learning }\end{array}$ & 484 & 40 \\
\hline 2018-02- 19 & Google Scholar & $\begin{array}{l}\text { Primary Health Care } \\
\text { and Experiential } \\
\text { learning }\end{array}$ & 239000 & 84 \\
\hline $2018-02-22$ & $\begin{array}{l}\text { EBscohost (Academic search complete, } \\
\text { Health Source: Nursing/Academic } \\
\text { Addition, MEDLINE) }\end{array}$ & $\begin{array}{l}\text { Primary Health Care } \\
\text { and Experiential } \\
\text { learning }\end{array}$ & 226 & 17 \\
\hline $2018-02-23$ & Open access & $\begin{array}{l}\text { Primary Health Care } \\
\text { and Experiential } \\
\text { learning }\end{array}$ & 308 & 2 \\
\hline 2018-02-23 & World Health Organisation & $\begin{array}{l}\text { Experiential learning } \\
\text { Training Policy and } \\
\text { guidelines }\end{array}$ & 2 & 0 \\
\hline $2018-02-23$ & Department Of Health & & 0 & 0 \\
\hline $2018-02-23$ & HealthSETA & & 1 & 0 \\
\hline Total & & & 240021 & 143 \\
\hline
\end{tabular}




\begin{tabular}{lc}
\hline Duplicates & 14 \\
\hline Total Eligible & 129 \\
studies for abstract & \\
screening & 29 \\
\hline Full article & \\
screening & 4 \\
\hline Data extraction & 4 \\
\hline Quality Appraisal & \\
\hline
\end{tabular}

\section{Appendix B}

Full article screening results

\begin{tabular}{|c|c|c|}
\hline Author and Year & Reviewer 1: Response & Reviewer 2: Response \\
\hline Baum, 2000 & 0 & 0 \\
\hline Becker, 2015 & 0 & 0 \\
\hline D’Lugoff, 2005. & 0 & 0 \\
\hline de Oliveira, 2015 & 1 & 1 \\
\hline Dornan, 2009 & 0 & 0 \\
\hline Evans, 2011 & 1 & 0 \\
\hline Gosen, 2004 & 0 & 0 \\
\hline $\mathrm{Hu}, 2015$ & 1 & 1 \\
\hline Kemeny, 2006 & 0 & 0 \\
\hline Kokotailo, 1995 & 0 & 0 \\
\hline Kolb, 2001 & 1 & 0 \\
\hline Langridge, 1998 & 0 & 0 \\
\hline Lockhart, 1997 & 0 & 0 \\
\hline Macaulay, 1999 & 0 & 0 \\
\hline Manley, 2009 & 1 & 0 \\
\hline Mashamba-Thompson,2016 & 1 & 1 \\
\hline McDonald, 2011 & 0 & 0 \\
\hline Munyewende, 2014 & 1 & 1 \\
\hline Pagano, 2009 & 0 & 0 \\
\hline Plsek, 2001 & 0 & 0 \\
\hline Prose, 2013 & 0 & 0 \\
\hline Stanley, 1993 & 0 & 0 \\
\hline Tess, 2009 & 0 & 0 \\
\hline Thornley C.2000. & 1 & 0 \\
\hline Thorpe, 2004 & 0 & 0 \\
\hline Well,1996. & 0 & 0 \\
\hline Wee, 2010 & 1 & 0 \\
\hline Weight, 2000 & 0 & 0 \\
\hline wharf, 1999 & 0 & 0 \\
\hline
\end{tabular}




\section{Appendix C}

Stata output for the above results: Level of agreement calculation Expected

\begin{tabular}{cccccc} 
Agreement & Agreement & Kappa & Std. Err. & Z & Prob $>Z$ \\
\hline $82.14 \%$ & $62.76 \%$ & 0.5205 & 0.1658 & 3.14 & 0.0008
\end{tabular}

\begin{tabular}{|c|c|c|c|}
\hline & | Controls & & \\
\hline Cases & Exposed & Unexposed & Total \\
\hline Exposed & 4 & 5 & 9 \\
\hline Unexposed | & 0 & 19 & 19 \\
\hline Total | & 4 & 24 & 28 \\
\hline
\end{tabular}

McNemar's chi2 $(1)=\quad 5.00 \quad$ Prob $>$ chi $2=0.0253$

Exact McNemar significance probability $\quad=0.0625$

Proportion with factor

Cases $\quad .3214286$

Controls $\quad .1428571 \quad$ [95\% Conf. Interval $]$

$\begin{array}{lccccc}\text { difference } & .1785714 & .0009971 & .3561457 & & \\ \text { ratio } & 2.25 & 1.083823 & 4.670965 & \\ \text { rel. diff. } & .2083333 & .0458559 & .3708108 & \\ \text { odds ratio } & . & .9163559 & . & \text { (exact) }\end{array}$

\section{Appendix D}

MMAT results

\begin{tabular}{lllll}
\hline Study Reference & Study Design & Reviewer 1 & Reviewer 2 & Overall Score \\
\hline De Oliveria et al., 2015 & Qualitative & $100 \%$ & $80 \%$ & $80 \%$ \\
Munyewende et al., 2015 & Qualitative & $100 \%$ & $80 \%$ & $80 \%$ \\
Wee, 2010 & Quantitative Descriptive & $100 \%$ & $100 \%$ & $100 \%$ \\
\hline
\end{tabular}

\section{Copyrights}

Copyright for this article is retained by the author(s), with first publication rights granted to the journal.

This is an open-access article distributed under the terms and conditions of the Creative Commons Attribution license (http://creativecommons.org/licenses/by/4.0/). 